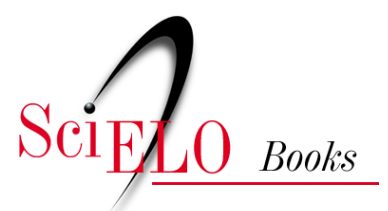

\title{
Cidades novas em seu contexto
}

\author{
Ricardo Trevisan
}

\section{SciELO Books / SciELO Livros / SciELO Libros}

TREVISA, R. Cidades novas em seu contexto. In: Cidades novas [online]. Brasília: Editora UnB, 2020, pp. 37-53. Pesquisa, inovação \& ousadia series. ISBN: 978-65-5846-158-6. https://doi.org/10.7476/9786558461586.0004.

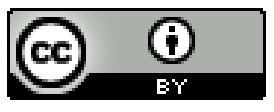

All the contents of this work, except where otherwise noted, is licensed under a $\underline{\text { Creative }}$ Commons Attribution 4.0 International license.

Todo o conteúdo deste trabalho, exceto quando houver ressalva, é publicado sob a licença Creative Commons Atribição 4.0.

Todo el contenido de esta obra, excepto donde se indique lo contrario, está bajo licencia de la licencia Creative Commons Reconocimento 4.0. 


\section{Cidades novas em seu contexto}

Estação de partida: Belo Horizonte, Minas Gerais.

Na última década do século XIX, nasce na região das Minas Gerais uma nova cidade: Belo Horizonte. Uma decisão político-econômica que transferiu a sede da capital mineira de Ouro Preto para o sítio na Serra do Curral, escolhido dentre outras quatro possibilidades mapeadas ao longo de dois anos de levantamento por uma comissão de técnicos especialistas. Uma decisão envolta por ideais - positivista e utópico - e permeada por um caráter simbólico: o de "expressar o novo Brasil que se pretendia construir com a República” (LEME, 2005, p. 223).

O projeto da nova capital teve início em 1893. A convite do governador Afonso Augusto Moreira Pena, o engenheiro civil Aarão Leal de Carvalho Reis (1853-1936) chefiou a Comissão Construtora da Nova Capital, com a qual colaboraram outros engenheiros formados na Politécnica do Rio de Janeiro, além de arquitetos-projetistas e artistas de renome internacional. Uma fase considerada por Berenice M. Guimarães (1996, p. 127) como “centralizadora, cientificista e utópica de construção da cidade”. Aarão Reis permaneceu somente até maio de 1895, quando foi substituído pelo engenheiro Francisco de Paula Bicalho (18471919), responsável pela condução da obra até a inauguração da cidade em 12 de dezembro de 1897.

Aarão Reis era engajado em movimentos da época, como o abolicionismo e o republicanismo, mas foi no positivismo, pelo viés filosófico da teoria, que pautou sua obra-prima. ${ }^{1}$ Ao recorrer à ciência como uma fórmula para solucionar questões humanas da época, o engenheiro idealizou o plano de Belo Horizonte a partir de

Antes de Belo Horizonte, há informações de que o engenheiro paraense havia aplicado seu conhecimento técnico no plano urbanístico de Soure, na Ilha do Marajó, no estado do Pará. 
problemas tecnicistas, como o de infraestrutura, deixando para segundo plano os aspectos de embelezamento.

A área urbana é composta por duas malhas quadriculadas - uma conformada por vias de 20 metros de largura a cada 120 metros, a outra com vias de 35 metros de largura a cada 800 metros -, sobrepostas a 45 graus, à semelhança dos planos de Washington (1791), Barcelona (1855) e La Plata (1882). Tal sobreposição possibilitou o surgimento de pattes-d'oie ou tridentes, cruzamentos de ruas e avenidas, resultando numa série de pontos perspécticos, geralmente ocupados por edifícios de importância cívica ou artística, aos moldes do urbanismo barroco de Versalhes (1664), de Karlsruhe (1715) ou da Paris haussmanniana (1851). A setorização de funções abrangia áreas residenciais (com tipologias diferentes), administrativas e de serviços. Mas as zonas comerciais e industrial não receberam a mesma atenção. Um grande parque municipal (800 por 800 metros), delineado por um paisagismo pitoresco, completou o esquema. A zona suburbana foi separada da urbana por uma avenida de contorno e dividida em superquadras de 250 por 250 metros para abrigar pequenas propriedades rurais, cemitério, estação de tratamento de esgoto, matadouro, reservatórios d’água etc. Após a zona suburbana, estabeleceu-se a rural e suas grandes propriedades agrícolas, responsáveis por abastecer a demanda alimentícia da nova capital. Desse modo, essas duas zonas periféricas criaram um cinturão verde de modo a trazer o campo para a nova capital, bem como conter seu crescimento.

Essa estrutura geral antecipou, em alguns anos, a proposta semelhante de Ebenezer Howard para a sua cidade-jardim de 1898. Todavia, seu projeto - previsto para 30 mil habitantes e com perspectivas de chegar a 200 mil com as três zonas - foi concebido mesmo antes da escolha do sítio, gerando, após a construção, incongruências entre o traçado idealizado e a topografia irregular existente. 
Cidades novas em seu contexto

Figura 2: Belo Horizonte

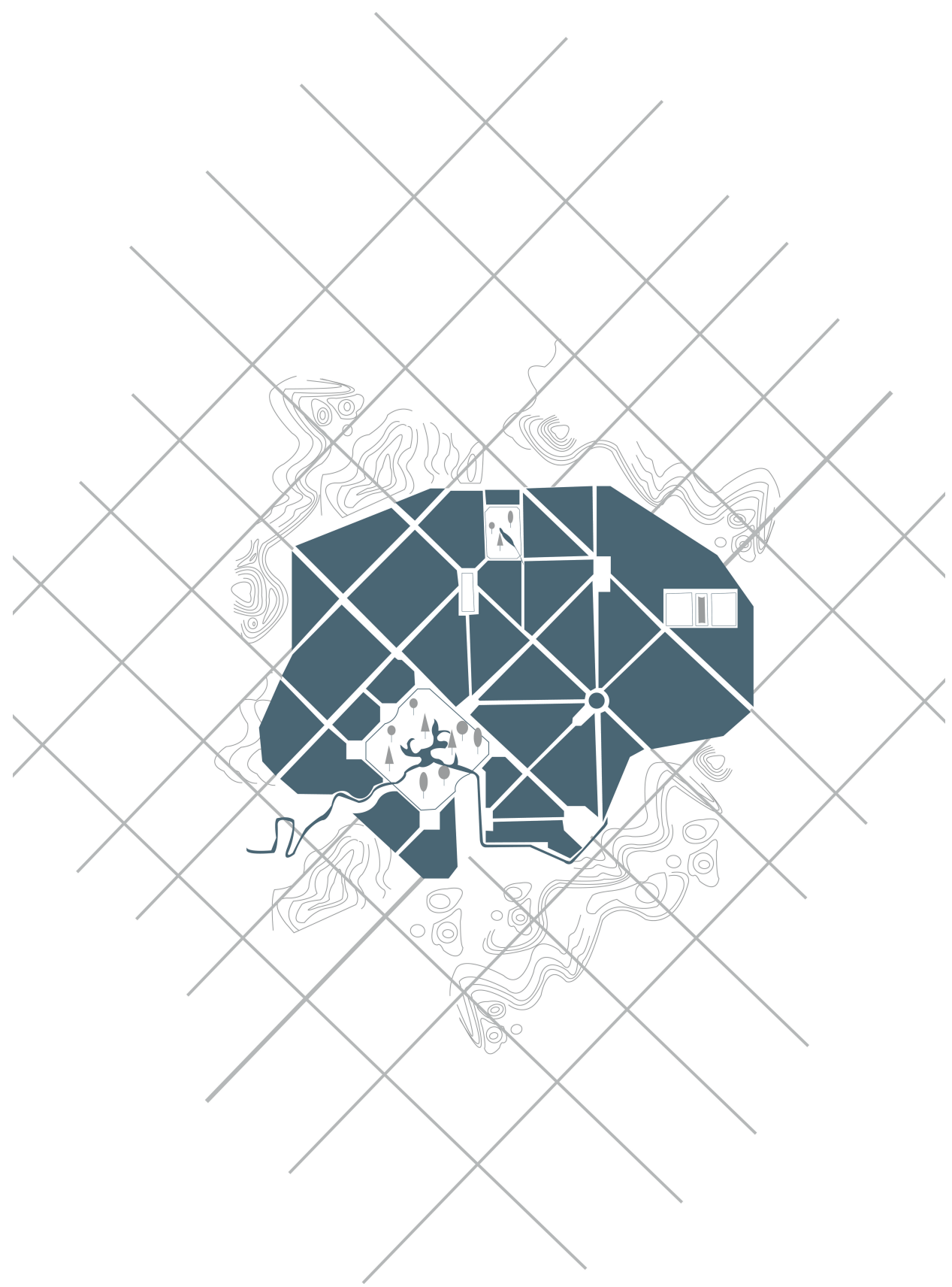


Belo Horizonte foi a materialização de um planejamento científico e racional, “a concretização da primeira utopia urbana brasileira” (GUIMARÃES, 1996, p. 123) na tradição socialista do século XIX. Originalidade à parte, o caráter utópico perceptível no plano de Aarão Reis foi resultado de sua intenção em construir um “protótipo de cidade”, destinado a criar uma sociedade melhor mediante uma nova ciência - o urbanismo - e sob uma nova forma de governo - o republicano. Para Reis, o urbanismo podia tirar proveito de todas as inovações tecnológicas disponíveis para fomentar melhorias sociais e conter as condições caóticas geradas pela industrialização que se iniciava em território nacional. O espaço urbano da nova capital deveria refletir e representar o poder executivo pela monumentalidade e pela organização da sociedade mediante uma convivência harmoniosa entre as diferentes classes sociais.

Positivistas e utópicos, os ideais de Belo Horizonte são aqui introduzidos como trampolim para discutirmos o contexto no qual se insere a temática cidades novas. Em consulta ao Dicionário Houaiss da Língua Portuguesa, contexto, do latim contextus, significa "a inter-relação de circunstâncias que acompanham um fato ou uma situação”. Considerando CNs como um fato, devemos, inicialmente, compreender as circunstâncias que as envolvem. Para isso, selecionei dois trajetos: primeiro, situar CNs enquanto um produto do urbanismo; segundo, revelar o caráter utópico que muitos de seus exemplares, ou os mais significativos na história das cidades, contêm. Duas circunstâncias que nos ajudarão a compreender melhor o universo das CNs.

\section{Cidades novas como um tipo do urbanismo}

Assim como Belo Horizonte, a disciplina urbanismo tem suas raízes no positivismo do século XIX. Foi Ildefons Cerdà i Sunyer (1815-1876), engenheiro-arquiteto espanhol idealizador do plano para a nova Barcelona (1855-1875), que se apropriou da palavra urbs para designar a ciência de organização espacial das cidades, o Urbanismo - termo que não deve ser confundido com seu homônimo, 
que se refere à acepção corrente na arte de desenhar as cidades e seus monumentos, presente desde a origem das cidades (PENNA, 1958).

Ao tornar público seu tratado Teoría general de la urbanización em 1867, Cerdà acreditava, pela primeira vez na história, ter dado status científico à criação e ao planejamento das cidades. Para ele, caberia ao urbanista verificar as regras e as leis contidas nas cidades espontâneas, enquadrá-las em teorias gerais e aplicá-las na concepção e organização de novos espaços.

Historicamente, não há conhecimento de uma sociedade cuja produção do espaço construído tenha surgido de uma disciplina autônoma, inclusive no Renascimento (CHOAY; MERLIN, 2005). Na Antiguidade e no Medievo, a organização do espaço urbano resultava do funcionamento de algumas práticas sociais, em particular a religiosa e a política, cuja permanência histórica teve por efeito constituí-las em padrões (tipos) reproduzidos ao fio do tempo. Acrescentam-se, ainda, como possíveis causas: textos de origem sagrada, produzindo na China cidades como expressão do universo; assentamentos-modelo reproduzidos no decorrer de processos colonizadores da Grécia e do Império Romano; ou propostas originais concebidas para fins precisos, como Bagdá, pela vontade de um príncipe.

Um sopro de mudança nesse processo foi dado na Itália do século XV, quando Leon Battista Alberti (1404-1472) escreveu De re Adificatoria (1443-52) - um tratado de arquitetura oferecido ao papa Nicolas V e publicado após sua morte, em 1485. Para Alberti, a arte de edificar era efetivamente uma disciplina teórica e aplicada, uma disciplina autônoma. A partir daí, uma vez em posse das regras e dos princípios estabelecidos pelo genovês, o arquiteto se tornou o grande organizador do espaço. Cabia a ele estruturar e edificar o quadro da vida humana, desde a paisagem rural, as estradas e os portos, até as cidades, seus jardins, seus planos e suas edificações. Portanto, poderíamos afirmar que Alberti antecipou em quatro séculos a ideia de autonomia e o campo de atuação propostos por Cerdà. Poderíamos... se não levássemos em consideração os contextos ideológico-temporais diferentes. Alberti constrói sua ideia num período pré-Revolução Industrial, em que 
a ciência moderna ainda não existia e o modelo de produção industrial ainda não havia transformado a sociedade urbana e o seu espaço. Na proposição albertiana, identificamos apenas uma visão estética de criação e planejamento urbano - a arte de embelezar as cidades -, que permeará o Renascimento e o Barroco e que, para o conjunto dos teóricos urbanistas pós-Revolução Industrial, salvo algumas exceções, como Camillo Sitte, não passaria de algo secundário.

O pensamento cerdaniano vem da Revolução Industrial e de seus efeitos imediatos no espaço urbano, de uma tradição utopista e positivista do século XIX, além da experiência espanhola em implantar CNs em terras colonizadas. Cerdà testemunhou o progresso de novas disciplinas, em particular da biologia e da história, das quais emprestou paradigmas e dados para postular uma ciência universal de planejamento. Trata-se, portanto, da primeira ocorrência de um gênero textual específico que os estudiosos franceses Françoise Choay e Pierre Merlin (2005, p. 914) nomeiam de "teoria do urbanismo”, e que, até os anos 1960, foi seguida por uma linha ininterrupta de ensaios similares.

Arturo Soria y Mata e sua Cidade linear (1882), Camillo Sitte e sua Cidade artística (1889), Ebenezer Howard e sua Cidade-jardim (1898), Tony Garnier e sua Cidade industrial (1917), Frank Lloyd Wright e sua Cidade evanescente (1932), Le Corbusier e sua Cidade modernista (1933), entre outros, propunham a organização espacial da cidade sob a forma de teoria, com pretensão científica e apresentada em modulações originais.

Todavia, durante o século XX, o urbanismo sai do domínio quase exclusivo de engenheiros e arquitetos para se tornar campo de estudo de outras ciências. Geógrafos, historiadores, economistas, antropólogos, sociólogos, advogados, psicólogos etc. assumem a tarefa de atribuir métodos inéditos de análise e diagnóstico ao espaço urbano, cabendo ao arquiteto-urbanista trabalhar, especificamente, sobre teorias normativas da cidade ou com projetos urbanísticos. A urbanización de Cerdà, originalmente singular e coesa, ganha, assim, outros sentidos, como: "história da 
urbanização, estudo da ecologia urbana, análise do funcionamento de sistemas urbanos” (AHTIK, 1969, p. 366, tradução nossa). ${ }^{2}$

Independentemente de tal transformação, o urbanismo se consolida e se disciplina no século XX, configurando-se como cátedra em universidades, tornando-se campo de atuação de vários profissionais e metamorfoseando-se em designações variadas.

Se, em países de língua latina, ou mesmo na Alemanha, o urbanismo recebe apenas um único termo sintetizador: urbanismo em espanhol, urbanismo ou urbanistica em italiano, urbanisme em francês, Städtebau em alemão, nos países anglo-saxônicos foi atrelado a um conjunto de locuções, como: civic design, town planning, city planning, urban planning, townscape, urban design, sendo urbanism apenas recentemente empregado nos Estados Unidos da América.

Segundo diferentes conceituações, o urbanismo pode ser, alternativamente: "a mais bela, a mais completa das artes, o lugar do conflito e da simbiose entre o gênio criador e as necessidades da multidão” (DELOUVRIER apud TILLIETTE, 1985, p. 13); “uma técnica social [com função de] adequar o espaço físico às necessidades e à dignidade da moradia humana e a todas as aspirações comunitárias” (BAYER apud GUIMARÃES, 2004, p. 2); “o conjunto de disciplinas científicas e artísticas que estudam a problemática da menor unidade territorial, que administrativamente tem por sede uma cidade” (FERRARI, 2004, p. 370); “um estilo de vida [ou] o conjunto das ciências que estudam o urbano” (VILLAÇA, 1999, p. 180); ou, pela visão reducionista, “um subconjunto do planejamento urbano”. (SOUZA, 2001, p. 58).

Seja qual for a definição ao fio da história - arte, técnica e/ou ciência da organização espacial dos estabelecimentos urbanos -, considero o urbanismo, aos moldes do positivismo, como uma “casa de muitos compartimentos” (CARVALHO apud GUIMARÃES, 1996, p. 126). Compartimentos que podem ser separados em: elementos, espécies, modelos, táxons ou tipos, como fizeram outras ciências contemporâneas (biologia, física, química, história etc.), a fim de disciplinar, arranjar,

2 “[...] histoire de l'urbanisation, étude de l'écologie urbaine, analyse du fonctionnement des systèmes urbaines [...]." 
ordenar ou organizar a "casa”. Uma organização de que me aproprio, articulo e emprego nesta obra, visando a auxiliar sua compreensão.

Sinteticamente, além do conhecimento, da reflexão, do saber científico e da arte da criação (sempre presentes no universo urbanístico), decomponho o urbanismo em dois compartimentos distintos: prática e produto, possuindo cada um deles seus tipos específicos.

A prática no urbanismo corresponde às atividades desempenhadas por profissionais da área com o objetivo de atender a uma determinada demanda empreitada pelo poder público e/ou privado, visando à melhoria das condições de vida do morador (ou grupo de moradores) de uma cidade ou região urbanizada. Dentre as práticas existentes, cito: projeto, plano, proposta, traçado, planejamento, embelezamento, melhoramento, paisagismo, desenho, reforma, preservação, intervenção etc.

Já o produto seria o resultado, teórico ou físico, de tais ações urbanísticas, como classificaram o sociólogo Peter Willmott (apud CLAPSON, 1998) e o urbanista Flávio Villaça (1999). O primeiro identifica como produto: os subúrbios periféricos, as cidades novas, as cidades expandidas e o redesenvolvimento de áreas centrais; o segundo amplia o escopo, reconhecendo, além das CNs: os planos de melhoramentos e embelezamento, o planejamento urbano stricto sensu, o zoneamento, o urbanismo sanitarista, os planos de infraestrutura urbana. Enriqueço a lista com: as vilas operárias, os conjuntos habitacionais, a reforma de áreas portuárias, os planos viários, as teorias urbanas, os planos gerais, os planos diretores e os planos de desenvolvimento estratégico.

O arquiteto Guy Burgel, em palestra ministrada no Conservatoire National des Arts et Métiers em Paris (5 de junho de 2008), salientou que há duas possíveis soluções para os problemas urbanos: reconstruir a cidade sobre a cidade (prática), por meio de planos de reestruturação, renovação etc. (produtos); ou criar (prática) cidades alhures (produtos). Prática e produto, compartimentos que nos auxiliam a enquadrar CNs como um tipo produzido pelo urbanismo. Um sistema classificatório que pode ser sequenciado, detectando, no conjunto, seus diferentes tipos: pela função original (administrativa, colonizadora, turística etc.), pelo traçado (em malha, 
radioconcêntrico, linear, modular etc.), pela filiação teórica (albertiana, modernista, howardiana etc.) ou por quaisquer outras possibilidades que possam surgir.

Ao evocar o caso de Belo Horizonte - um empreendimento público, planejado para ser a nova capital de Minas Gerais, implantado estrategicamente sobre a Serra do Curral, projetado pelo engenheiro Aarão Reis e fundado após quatro anos de sua concepção -, posso afirmar que se trata de um tipo de CN classificável ou como uma CN administrativa ou como uma CN em malha. Método igualmente válido para Barcelona: CN de expansão ou CN cerdaniana. CNs distintas, mas ambas consideradas CNs, um tipo do urbanismo.

Portanto, ao contextualizar as CNs na ciência urbanística, destacando-as do universo de produções existentes, abro caminho para trabalhar seus inúmeros aspectos qualificativos, como o conceito de cidade ideal.

\section{Cidades novas como ideais: da utopia à realidade}

Belo Horizonte foi um ideal de Aarão Reis posto em prática em fins do século XIX. Uma utopia que se tornou realidade graças às conjunturas propícias daquele momento. Como a capital mineira, outras cidades ideais surgiram a partir de propostas inovadoras, consideradas por muitos devaneios de seus criadores; já outras permaneceram fictícias, como utopias. Realizadas ou utópicas, tais cidades ou ideais compõem o universo das CNs.

Em Storia dell’Utopia (1969), o sociólogo e historiador norte-americano Lewis Mumford define utopia como:

[...] o estágio último da loucura humana ou da esperança humana: inúteis sonhos de perfeição em uma Terra do Nunca, um país que não existirá, ou uma pura tentativa racional de reconstruir o ambiente humano, suas instituições e até a imperfeição de sua 
natureza, com propósito de aumentar a oportunidade na vida a cada dia. (MUMFORD, 1969, p. 1, tradução nossa). ${ }^{3}$

Loucura ou esperança, indícios revelam que o termo utopia foi forjado, originalmente, pelo escritor inglês Thomas More (1478-1535), em sua obra homônima de 1516, a partir de raízes gregas. Surgiu do substantivo tópos (lugar) e duas partículas, o prefixo eu (boa qualidade) e ou (nenhum), sendo também utilizado pela sua contração $u$. Significa, respectivamente, o espaço bom (eutopia) e o espaço que não existe (utopia). ${ }^{4}$

Contudo, as criações de uma sociedade perfeita habitando uma cidade-modelo datam de muito antes do século XVI. Da República (384-377 a.C.) de Platão ou do Monte Athos (século $1^{\circ}$ d.C.) de Vitrúvio às propostas de cidades em grandes estruturas da segunda metade do século XX - Brasília de Rino Levi (1957), Tóquio de Kenzo Tange (1960) e Walking cities de Ron Herron (1964) -, as cidades ideais são símbolo de uma busca pela felicidade original perdida, perseguida desde as tradições bíblicas (Éden, a terra prometida). ${ }^{5}$

Tais proposições sempre alimentaram a humanidade e ocuparam o imaginário de um grande número de filósofos, escritores e historiadores. Em referência a Anatole France, sem as utopias, os homens estariam ainda vivendo em cavernas, miseráveis e nus. Foram os utópicos que traçaram as linhas das primeiras cidades (apud BERNERI, 1950, s/p). Saídas de sonhos generosos, esses intentos

3 “[...] lo stadio ultimo dell'umana follia o dell'umana speranza: inutili sogni di perfezione in uma Never-Never Land, il paese che non esisterà, oppure tentativi razionali di ricostruire l'ambiente umano, le sue istituzioni e perfino le imperfezioni dela sua natura, allo scopo di aumentar ele opportunità nella vita di tutti i giorni.”

4 Há ainda a Kakotopia (lugar ruim), termo formulado pelo biólogo, sociólogo e planejador urbano escocês Patrick Geddes (1854-1932), em sua obra Cities in evolution: an introduction to the town-planning movement (1915), para referir-se à cidade industrial e seus "bairros pobres, semi pobres e muito pobres” (GEDDES, 1994, p. 8).

5 A continuidade da dimensão suprema na utopia pode ser verificada nas pinturas medievais ou renascentistas, que transformavam o espectador em olho celeste (deuses) ao lhe possibilitar visualizar a cidade de um ponto de vista (voo de pássaro) que jamais existira até então. 
tornaram-se realidades benéficas. Utopia, segundo o escritor francês, seria o princípio de todo o progresso, um ensaio para um futuro melhor.

Contrário à ideia da utopia platônica, Anatole France indica a realidade como único caminho para uma vida melhor. Para ele, Platão criou um discurso de utopia que aprisionou todos os utopistas posteriores. Sem tirar-lhe os méritos de gênio, considera o filósofo como "um protofascista”, que acreditava no papel de comando da elite, na autarquia, no uso da mentira para governar, no militarismo, e em muitos outros métodos. Seguindo o raciocínio, Lewis Mumford (1969) acredita que a maioria dos utopistas clássicos apresentava tendências ditatoriais, tentando impor às múltiplas atividades humanas e ao jogo de interesse da sociedade uma disciplina monolítica. ${ }^{6}$

Lewis Mumford irá pensar a utopia como algo oposto ao espírito unilateral, partidário, especializado. Para o autor, quem segue o método utópico deve considerar a vida no presente e em todos os pontos de vista, ou seja, “como um conjunto interrelacionado [...] como um órgão junto de partes suscetíveis a melhor organização, com as quais é importante manter o equilíbrio” (MUMFORD, 1969, p. 4, tradução nossa). ${ }^{7}$

Românticas ou realistas, as definições encontradas na literatura também nos permitem estabelecer um entendimento da utopia a partir dos seguintes aspectos: temporal, político-econômico-social e físico.

Pelo viés temporal, a busca nostálgica por um passado perdido e o anseio por um futuro inatingível fizeram da utopia uma negação do presente. Ciente disso, Giulio Carlo Argan afirma:

6 Como exemplo, cita-se a proposta do ditador italiano Benedito Mussolini (1883-1945) para a Esposizione Universale di Roma (EUR) de 1942: um núcleo urbano iniciado em 1939, projetado pelo arquiteto Marcello Piacentini e equipe, alocado na periferia da capital italiana e marcado por uma arquitetura rígida, simétrica e homogênea - personificação, nesse caso, do poder e glória de um regime totalitário.

7 “[...] come um tutto interrelazionato [...] come um orgânico insieme di parti suscettibile di migliore organizzazione, di cui è importante mantenere l'equilibrio [...].” 
O que atrai, no passado e no futuro, é justamente o não estar "presente”. É até mesmo possível reunir as duas categorias aparentemente contraditórias em uma só e considerar tudo como utopia: entendida não tanto como prefiguração de um tempo melhor, mas como desgosto e impossibilidade de viver no atual. (apud PESSOA, 2006, p. 101).

Na história, as utopias aparecem mais regularmente em períodos de transição e em épocas de grandes incertezas. Exemplo disso são as proposições dos “socialistas utópicos” nos séculos XVIII e XIX , como saídas alternativas para a florescente cidade industrial e suas adversidades. Chamados de "progressistas” por Françoise Choay (1997), esses pensadores acreditavam, com base na enorme adaptabilidade da sociedade, que bastava renegar o passado para se obter a chave de um futuro melhor, previsto racionalmente em todos os aspectos. Foi assim quando o escritor francês Etienne Cabet (1788-1856) criou, em 1840, a cidade de Icara, capital de um Estado fictício: Icaria, descrita por ele em seu livro Voyage en Icarie. Ou quando o médico inglês Benjamin Ward Richardson (1828-1896) formulou, também em livro, a cidade de Hygeia (1876) - Cidade da Saúde.

Outros criadores evocaram um tipo antigo como referência fundamental em todas as tentativas de remodelação e de reestruturação urbana - os "culturalistas" (CHOAY, 1997). Bandeira hasteada por Camillo Sitte (1843-1903), ao resgatar para sua Cidade artística as características existentes nas cidades medievais, em especial as praças; e pelos filósofos ingleses John Ruskin (1818-1900) e William Morris (1834-1896) que, unidos ao arquiteto Richard Norman Shaw (1831-1912), lideraram o movimento Arts \& Crafts. ${ }^{8}$

8 O Arts \& Crafts (Artes e Ofícios), criado pelos filósofos Ruskin e Morris no século XIX, opunha-se aos modos de trabalho e de produção impostos pela industrialização, primando os estudos históricos e o artesanato. A base desse Movimento estava não no progresso, mas na cultura, no resgate do caráter social e artesanal da produção e na instituição da arte na vida cotidiana das pessoas. 
Mas, em ambas as vertentes, seja progressista ou culturalista, há um ponto em comum: a rejeição à realidade, nutrida por um sistema político-econômico-social insatisfatório.

Paralelamente ao fator tempo, a crítica ao sistema vigente faz da utopia uma busca pela sociedade ideal, associada às noções de evolução, de perfeição e de progresso. Geralmente, o interesse individual deveria ser substituído pelo coletivo, como um ponto inicial de transformação do mundo. Nesse sentido, o norte-americano Edward Bellamy (1850-1893) futuriza, em seu livro Looking backwards (1888), a cidade de Boston no ano 2000 como uma sociedade centralizada e igualitária, na qual direitos sociais são respeitados e deveres são repartidos com a máquina a serviço do homem (BELLAMY, 1942). Agrupamento social similar ao Falanstério, do francês Charles Fourier (1772-1837): um único edifício ocupado por 1,6 mil pessoas em busca da harmonia universal - uma grande máquina de habitação destinada a criar uma vida comunitária estreitamente integrada.

A fim de atingir o perfeito desenho social, a maioria dos utopistas formula, simultaneamente, um novo habitat e, invariavelmente, uma nova cidade. É como se sociedade e cidade não pudessem ser dissociadas. Assim, o espaço urbano - a materialização do sonho - sempre foi o cenário das utopias, sendo apresentado em diferentes trabalhos: Cidade de Deus, de Santo Agostinho (410 d.C.), Sforzinda, de Antonio Averlino Filarete (1460), Abadia de Thelema, de François Rabelais (1532), Cristianópolis, de Johann Valentin Andreäe (1619), Cidade do Sol, de Tomaso Campanella (1623), Nova Atlântida, de Francis Bacon (1624), Oceana, de James Harrington (1656), Aventuras de Telêmaco, de François de Salignac de La Mothe-Fénelon (1699), Suplemento da viagem a Bougainville, de Denis Diderot (1772), além das propostas pós-Revolução Industrial, como as vilas industriais campestres do geógrafo russo Piotr Alexeevich Kropotkin (1842-1921).

Romanceadas em obras literárias como respostas a uma contrautopia (lugar inabitável) existente, tais criações também materializaram soluções urbanísticas originais, introduzidas em parcelas urbanas ou na totalidade de uma CN. Utópicos, radicais, 


\section{Cidades novas}

inovadores, polêmicos, criticados ou louvados, esses trabalhos tiveram a iniciativa de repensar, de modo revolucionário, a cidade caótica, fosse pelo planejamento urbano segundo as necessidades impostas (por exemplo, as obras do papa Sisto V em Roma, no século XVI, ou as intervenções de Haussmann em Paris do século XIX), fosse pela criação de CNs. Cidades-conceito que, elaboradas por pensadores e reformadores atentos à situação inquietante de uma determinada realidade, provocaram transformações físico-sociais mediante apropriações isoladas ou absolutas no decorrer do tempo.

Nessa direção, a utopia, vista por seu aspecto físico, recebeu atenção especial de Emmanuel Eveno em seu livro Utopies urbaines, de 1998. Para o autor, a utopia urbana é um ato político, cuja finalidade se divide, globalmente, em duas grandes famílias: as "utopias-espelhos” (utopies-miroirs) e as “utopias-projetos” (utopies-projets). A família das "utopias-espelhos” é aquela do mundo inverso - a sutil inversão ótica do espelho -, não destinado a ser real, mas instigador da imaginação. As “utopias-espelhos” representam um modo de expressão política e podem ser um ato de oposição, uma crítica ou uma contestação - ideia compartilhada pelo arquiteto francês Yannis Tsiomis, que define utopia como "uma contra realidade, uma inversão da realidade, termo a termo, uma versão de texto que construa outro espaço que não é inexistente, mas que seja uma inversão do espaço existente” (TSIOMIS, 2006, p. 71).

Por sua vez, a família de “utopias-projetos” se apresenta a partir de dois principais aspectos: as "utopias completas" e os "fragmentos de utopias”. As “utopias completas" repousam sobre um pragmatismo de uma nova fundação, justificado num ato revolucionário para organizar total e completamente uma nova sociedade. São utopias frequentemente associadas ao Renascimento, ao Iluminismo e a algumas CNs das Américas colonizadas. Ilustram esse caso a CN empresarial de Chaux, na França, projetada pelo arquiteto Claude-Nicolas Ledoux (1736-1806) e construída entre 1774 e 1779; e a norte-americana New Harmony, de 1824, planejada por Robert Owen (1771-1858).

Os “fragmentos de utopias” focalizam a temática a partir da dimensão projetiva, tendo os fragmentos o objetivo de assinalar que, no projeto, os princípios revolucionários e de nova fundação social são secundários. Nela, na dimensão 
projetiva, a arquitetura e o urbanismo são os meios mais claros de intervenção. Algo recorrente no século XX, quando o pragmatismo dilui o projeto utópico na tensão que existe entre projeto-decisão-realização, conferindo à utopia um lugar na elaboração do projeto. Essa forma utópica se justifica por sua exemplificação, acomodando experimentações limitadas no espaço urbano, como a Cidade marina de Kiyonori Kikutake, de 1968, e a Cidade sistemática urbano-fabril-agro-florestal na Amazônia, do arquiteto brasileiro Spencer Pupo Nogueira, dos anos 1980.

Figura 3: Cidade Marina

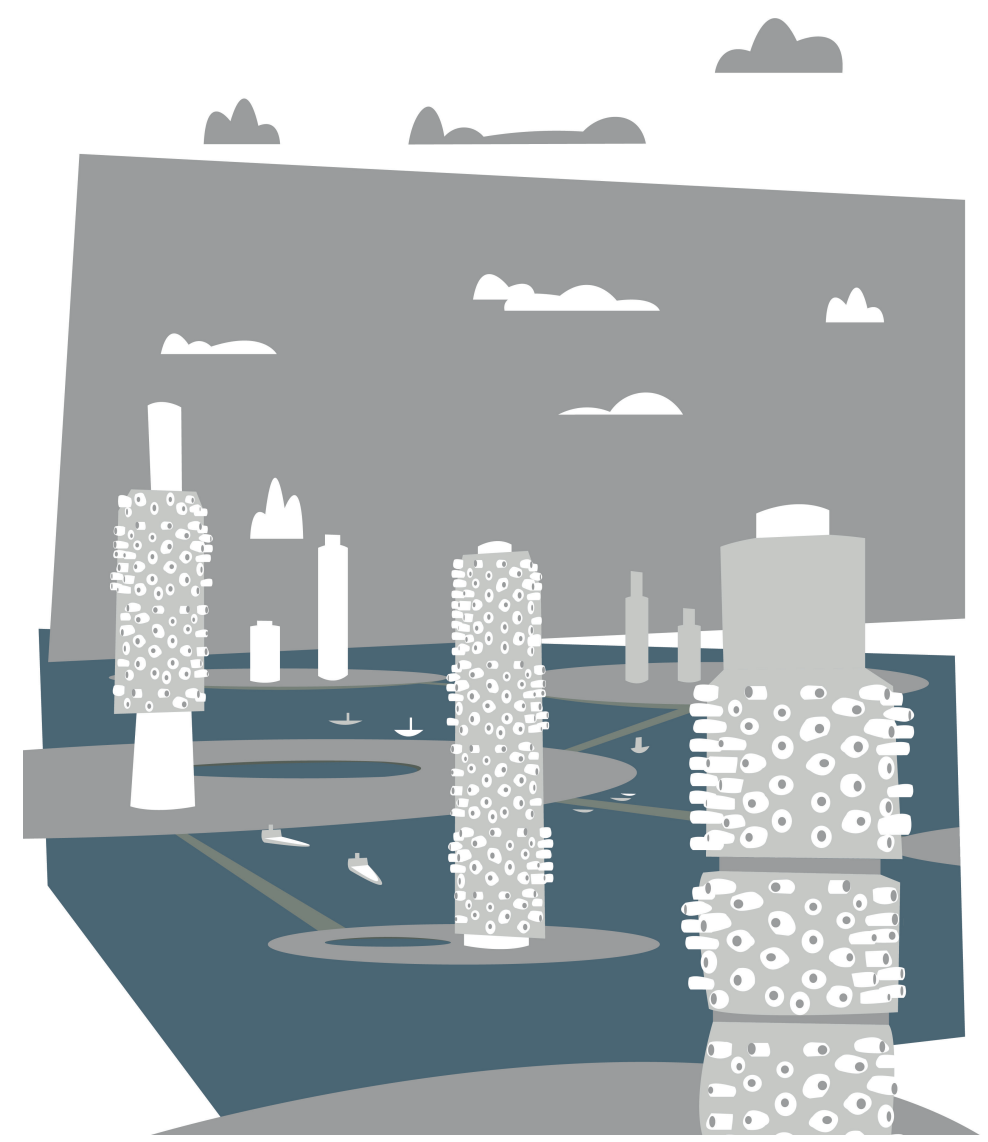


Essa utopia física, urbana e arquitetônica foi fomentada pelas inúmeras teorias originárias dos séculos XIX e XX. Seus genitores - Howard, Soria y Mata, Le Corbusier, Clarence Stein e Henry Wright, Frank Lloyd Wright, Buckminster Fuller, Cedric Price, Yona Friedman, Team X, Archigram, entre outros - foram responsáveis por uma rica produção de tipologias urbanísticas. Como consequência, tivemos a origem de diferentes CNs, idealizadas com o intuito de estabelecer um rumo a seguir, uma bússola colocada à disposição da sociedade.

Tais cidades ideais, assim como vimos no conceito de utopia, recebem diferentes definições. Michel de Certeau (1996) as conceitua a partir de uma tríplice operação: 1) a produção de um espaço próprio; 2) o estabelecimento de um não-tempo ou um sistema sincrônico; e 3) a criação de um sujeito universal e anônimo, que é a própria cidade. Hanno-Walter Kruft (1990) as apropria pela dimensão física: 1) a regularidade da projetação - plano regular - não precisa ser um critério obrigatório; e 2) a necessária correspondência estética entre utopia e forma da cidade ideal pressupõe que deve existir um procedimento reflexivo. Pier Luigi Giordano as coloca como excludentes dos aspectos sociais, obedecendo “apenas a um interesse prioritariamente formal, sem qualquer interesse no substrato humano, apenas com o gosto estético pelo traçado, ainda mais se este tiver por finalidade militar ou política” (GIORDANO, 1962, p. 181, tradução nossa). ${ }^{9}$ Patrick Boucheron (2002) segue o mesmo pragmatismo, considerando-as como uma simples cidade de fundação e tal fundação é, por definição, um gesto político.

De uma definição mais filosófica a outras taxativas e simplistas, as cidades ideais são uma realidade. Ao longo da história, identificamos exemplares que, mesmo não sendo efetivados (conceituais), acabaram por influenciar as práticas urbanísticas posteriores.

Tipos geométricos, simétricos, regulares, pontuados por uma centralidade; tipos fechados delimitados por muralhas, fossos, penhascos ou cinturões verdes;

9 “[...] solo per un interesse principalmente formale, senza alcun interesse per il substrato umano, solo con il gusto estetico del trattino, anche se ha fini militari o politici [...]." 
tipos bidimensionais (traçado) ou tridimensionais (tecido); essas cidades ideais saíram do campo virtual, da utopia, para se tornarem nossas cidades, uma realidade como Belo Horizonte.

Assumo que um mundo sem utopias, sem sonhos, sem CNs seria um mundo inerte, alienante, sufocante; e graças a elas tenho ânimo para continuar em nossa viagem que apenas se inicia. 